\title{
COVID-19 and inequalities: the need for inclusive policy response
}

\author{
Farah Naz $^{1}$ (D) Muhammad Ahmad ${ }^{2}$ Asad Umair ${ }^{1}$
}

Received: 11 September 2020 / Accepted: 22 June 2021 / Published online: 6 July 2021

(C) Springer Nature Switzerland AG 2021

\begin{abstract}
In this essay, the authors analyze the COVID-19 pandemic from the perspective of inequalities and socio-economic vulnerabilities. We argue that the current pandemic has been looked at mainly through the lens of biology, leaving sociological blind spots in the response to this pandemic that have had adverse effects. We conclude with the suggestion that apart from recommendations from health sciences, policy makers must also take into account local societal structures in order to design effective policies to control the contagion.
\end{abstract}

Keywords COVID-19 $\cdot$ Inequalities $\cdot$ Social policy

\section{Introduction}

The outbreak of COVID-19 plunged the world into a state of chaos and uncertainty. As fear and anxiety built up, governments around the world responded to the pandemic by imposing long, nationwide lockdowns in an attempt to "flatten the curve" - a term that refers slowing down the spread of the disease in order to prevent healthcare facilities from being overwhelmed by too many new patients. However, lockdowns and related strategies designed to minimize the spread of the pandemic, like

Farah Naz

farah.naz@uos.edu.pk

Muhammad Ahmad

muhammedahmad1321@gmail.com

Asad Umair

assadumair@yahoo.com

1 Department of Sociology and Criminology, University of Sargodha, Sargodha, Pakistan

2 Beaconhouse College Campus, Sargodha, Pakistan 
early detection, isolation of confirmed cases, and social distancing, were built and implemented on the assumption that COVID-19 is simply a health emergency that demands solutions from the life science alone. ${ }^{1}$ They failed to take into account how these strategies affect the social structure itself. Pandemics are social, economic, and biological phenomena (Geoffrey et al., 1992). By taking an approach that considers not only the biological but also the sociological aspects of a pandemic, better preventative strategies could have been devised.

In this short essay, we look at the COVID-19 pandemic from a sociological perspective to explain why health issues and related preventive measures are hard to separate from socioeconomic gradients. Social inequalities refer to unequal rewards and opportunities available to different groups of people occupying differential positions in the ladder of society. There are four important domains of inequality: socioeconomic, health, political, and cultural. Sociological research on inequalities and social stratification analyze the institutions and processes that might generate, maintain, and change the system of social inequalities in all theses domains (Stehr, 1999). We specifically bring forth a socioeconomic perspective on inequality to track disproportionate risks and consequence of COVID-19, as it is a significant feature of our $^{2}$ region.

\section{How the virus interacts with already existing societal inequalities}

In mainstream media, COVID-19 has been often called the "great equalizer" which transcends all forms of social and economic disparities (Mein, 2020). However, the history of pandemics shows that when epidemics or pandemics hit, they usually hit the poor first and worst (Daniels et al., 2000; Milyo \& Mellor, 1999). Pandemics not only cause severe economic damage, but they also often lead to and increase in wealth inequality (Furceri et al., 2020). Considering this, it is not surprising that this pandemic has disproportionately affected disadvantaged groups. However, the government response to the pandemic has not taken this into account, and most policies either ignore this problem or inadvertently make it worse. Here we paid particular attention to the situation in the South Asian Region, which is home to one-third of the world's poor. South Asian countries, despite many difference, largely share the same characteristics such as a large population, a weak healthcare system, high poverty rates, poor social protection systems, limited access to water and sanitation, and inadequate living spaces to maintain necessary physical distancing. They are also marked by extreme inequality of wealth.

In order to contain this pandemic, various measures to restrict mobility, including strict lock downs, were imposed. Though it helped to control the spread temporarily, and triggered optimism in the region that the pandemic had waned, this did not

\footnotetext{
1 This note belongs to the Topical Collection "Seeing Clearly Through COVID-19: Current and future questions for the history and philosophy of the life sciences", edited by G. Boniolo and L. Onaga.

${ }^{2}$ In order to make explicit possible limitations of this study and our positionalities, it should be clarified that the authors are from South Asian region.
} 
last long, and a new wave of COVID-19 is ravaging the region. Daily infections in India have gone past the 200,000 mark, bringing unprecedented hardship, especially for poor households. Because the current pandemic has been looked at by the states mainly through the lens of biology, sociological blind spots in the response to this pandemic have had adverse effects.

Containment measures such as lockdowns have especially done a disservice to the lower strata of society by affecting the livelihood of millions of people. Income levels have dropped, and there is sharp rise in poverty due to COIVD related containment measures. In Pakistan alone, about 12 million workers were laid-off due to lockdowns and the country's sluggish economic recovery. According to a report prepared by the Centre for Sustainable Employment at Azim Premji University (APU), during the lockdown period, nearly 230 million additional individuals fell below the national minimum wage poverty line in India. Whereas middle and upper class workplaces are often able to save jobs by "going virtual", that is usually not an option for most lower class workplaces which usually require in-person physical labor (Blundell et al., 2020).

The most vulnerable group during this pandemic has been those who have jobs in the informal sector-a group that represents 90 per cent of total employment in lowincome countries (ILO, 2018). This sector was hard hit during the pandemic; almost 1.6 billion informal workers have been affected by the resulting economic crisis worldwide (ILO, 2020a). Informality has an adverse impact on adequacy of earnings, occupational safety, and health and working conditions in general. Their condition makes it harder for them to follow current preventative measures, and even when they are able to follow them, these measures are less effective for them than for many other groups. For example, even when they self-isolate, informal workers are at a higher risk of infection due to overcrowded and unsanitary living conditions, food insecurity, lack of personal protective equipment, and lack of access to running water (ILO, 2020b).

Informal workers are also known to have poor healthcare (Ruiz et al., 2015), and without social protection, their future financial prospects seem bleak. The high rate of lay-offs has an adverse effect on the livelihood and food security of informal workers. Without any alternative income sources, lost income will result in an increase in relative poverty for informal workers and their families of more than 21 percentage points in upper-middle-income countries and 56 points in low-income countries (UNDP, 2020). The never-ending plight of informal workers, of which migrant workers are a large part, has brought out attention towards pronounced inequalities. Inadequacy of existing measures to deal with the health crisis is evident from the collapsing health and economic infrastructure.

COVID-19 has raised legitimate concerns about societal inequalities. A sociological perspective, which balances public health priorities with economic and social activities, is crucial when devising guidelines, policy responses, or recovery plans. Taking inequalities into consideration and devising social safety nets for the poor can better prevent the spread of epidemics now and in the future. Failure to gather and analyze data about inequalities based on wealth and political power misleads the policy debate. A multi-dimensional approach that incorporates a sociological perspective into its decision-making process is required. The social aspects of 
pandemics need to be better researched. When devising guidelines or implementing prevention plans, the needs and abilities of especially vulnerable groups (like informal workers) need to be considered.

\section{Concluding thoughts}

Now as we are approach almost two years of lockdowns, it is worth looking back in an attempt to see what went wrong, what could have been done differently, and how we should deal with such pandemics now and in the future. Health issues and related preventive measures are hard to separate from socioeconomic gradients. Though COVID-19 is primarily a health issue, to better prevent the spread of such epidemics, and to do so in a way that is not at the expense of the disadvantaged groups, we need to consider societal factors as well. Throughout this pandemic, we have seen government policies that aims primarily at reducing "number of infections," whilst ignoring, and sometimes even causing inequalties. While responding to COVID-19, policy makers should not have a solely numbers focused approach which does not factor in societal impact. In this short essay we do not claim to provide definite solution but want to raise questions that need serious consideration: In increasingly globalized and interconnected world, can we hold back such a contagion using harsh lockdown-type tactics while also taking into consideration the lived realities of working class, lower income people? Can we envision solutions that also deal with the issue of providing basic food security and social protection to disadvantaged groups?

\section{References}

Blundell, R., Dias, M. C., Joyce, R., \& Xu, X. (2020). Covid-19 and inequalities. Fiscal Studies, 41(2), 291-319.

Daniels, N., Kennedy, B., \& Kawachi, I. (2000). Is inequality bad for our health? Beacon Press.

Furceri, D., Loungani, P., Ostry, J. D., \& Pizzuto, P. (2020). COVID-19 will raise inequality if past pandemics are a guide. https://voxeu.org/article/covid-19-will-raise-inequality-if-past-pandemics-areguide Accessed 9 September 2020

Geoffrey, R., Kay-Tee, K., \& Michael, M. (1992). Rose's strategy of preventive medicine: The complete original text. Oxford University Press.

ILO (2020b). COVID-19 crisis and the informal economy immediate responses and policy challenges. https://www.ilo.org/wcmsp5/groups/public/@ed_protect/@protrav/@travail/documents/briefingnote/wcms_743623.pdf . Accessed 5 January 2021

ILO (2020a). ILO monitor: COVID-19 and the world of work. Third edition Updated estimates and analysis. $\quad$ https://www.ilo.org/wcmsp5/groups/public/---dgreports/---dcomm/documents/briefingnote/ wcms_743146.pdf . Accessed 5 January 2021

ILO (2018). Women and men in the informal Economy: A statistical picture. https://www.ilo.org/ wcmsp5/groups/public/---dgreports/---dcomm/documents/publication/wcms_626831.pdfAccessed 9 September 2020

Mein, S. (2020). COVID-19 and health disparities: The reality of 'the great equalizer. Journal of General Internal Medicine, 14, 1-2.

Milyo, J., \& Mellor, J. M. (1999). Is inequality bad for our health? Critical Review., 13(3-4), 359-372. 
Ruiz, M. L., Artazcoz, L., Martínez, J. M., Rojas, M., \& Benavides, F. G. (2015). Informal employment and health status in Central America. BMC Public Health. https://doi.org/10.1186/ s12889-015-2030-9

Stehr, N. (1999). The Future of Social Inequality. Society, 36, 54-59.

UNDP (2020). COVID-19 and human development: Assessing the crisis, Envisioning the recovery. http://hdr.undp.org/en/hdp-covid .Accessed 9 January 2021

Publisher's Note Springer Nature remains neutral with regard to jurisdictional claims in published maps and institutional affiliations. 